\title{
STUDI PENERAPAN DESAIN UNIVERSAL PADA MESJID MANARUL AMAL KAMPUS MERUYA DI UNIVERSITAS MERCU BUANA JAKARTA BARAT
}

\author{
Rachmita Maun Harahap, Henny Gambiro, Randi Sanjaya \\ Universitas Mercu Buana
}

\begin{abstract}
Abstrak. Penelitian ini bertujuan untuk mendeskripsikan studi penerapan desain universal pada mesjid Manarul Amal di kampus Meruya Universitas Mercu Buana bagi semua orang termasuk penyandang disabilitas. Prinsip desain universal dipilih berdasarkan pada kemungkinan yang diberikannya untuk mengeksplorasi setiap perlengkapan potensi untuk mengurangi atau bahkan menghilangkan penghalang fisik bagi penggunanya. Metode penelitian ini menggunakan metode deskriptif kualitatif. Instrumen penelitian ini adalah peneliti yang dibantu dengan pedoman observasi, pedoman wawancara dan pedoman dokumentasi berdasarkan kisi-kisi Peraturan Menteri Pekerjaan Umum Perumahan Rakyat No. 14/PRT/M/2017. Langkah-langkah analisis data yang dilakukan meliputi : reduksi data, penyajian data, dan pengambilan kesimpulan. Hasil penelitian menunjukkan bahwa elemen-elemen interior pada ruang mesjid Manarul Amal berupa sirkulasi, jalur pemandu, ramp, ruang sholat, ruang khotbah, ruang toilet, tempat wudhu, rak menyimpan alas kaki (sepatu dan kaki) dan atribut-atribut fasilitas mendukung belum memenuhi standar. Sementara dinding-dinding ruang tidak dilengkapi handraill, pencahayaan dan warna cukup memenuhi standar dan audio visual yang berada di sekelilingi ruang sholat tanpa dilengkapi TV text, alarm visual (suara memanggil saat akan sholat).
\end{abstract}

Kata kunci : desain universal, masjid, penyandang disabilitas, Manarul Amal

\begin{abstract}
This study aims to describe of study of universal design application at the Manarul Amal mosque on Meruya campus at Mercu Buana University for person with disabilities. Universal design principle is chosen based on possibilities it provides to explore each potential tool to reduce or even eliminate the physical barrier for its users. This research method uses a qualitative descriptive method. The instrument of this study was researchers who were assisted with observation guidelines, interview guidelines and documentation guidelines based on the grid Minister of Public Works Regulation No. 14 / PRT / M / 2017. The steps of data analysis carried out include : data reduction, data presentation, and conclusion. The results showed that the interior elements in the Manarul Amal mosque were in form of circulation, guiding paths, ramps, prayer rooms, sermon rooms, ablution rooms, shelves for footwear (shoes and feet) and supporting facilities attributes that didn't meet standard. While the walls of room aren't equipped with handraill, lighting and colors are sufficient to meet the standards and audio visual that is around the prayer room without a TV text, visual alarm (sound calling when praying).
\end{abstract}

Keywords : universal design, masjid, disabilities, Manarul Amal

Correspondence author: Rachmita Mau Harahap, rachmita.mh@mercubuana.ac.id, Jakarta, Indonesia 


\section{Pendahuluan}

\section{Latar Belakang}

Fasilitas fisik mesjid berdasarkan 7 prinsip desain universal belum menjadi terapan yang umum di Indonesia. Desain interior masjid yang ada tetapi belum diterapkan desain universal dengan mempertimbangkan kebutuhan pihak-pihak yang memiliki keterbatasan fisik, seperti pengguna kursi roda, tuna netra, tuna rungu, rentang usia tertentu, dan juga perbedaan jenis kelamin secara imbang. Masjid merupakan pusat kegiatan keagamaan, masjid adalah 'rumah Allah' di mana jamaah melakukan shalat. Shalat adalah ibadah penting dalam Islam yang dilakukan setidaknya lima kali sehari dan tidak dapat ditinggalkan kecuali kondisi yang sangat spesifik terjadi (seperti yang dijelaskan dalam Al Qur'an).

Negara, melalui Undang-Undang Penyandang Disabilitas No 8 tahun 2016 menyebutkan dan menjamin berbagai macam hak penyandang disabilitas tetapi sayangnya tidak secara khusus menyebut hak akses beribadah. Ditambah lagi, dalam peraturan bangunan di Indonesia, bangunan publik sebagaimana diatur oleh Undang-Undang Republik Indonesia No.28 tahun 2002 tentang Bangunan Gedung, pasal 27 dan dipandu oleh Peraturan Menteri Pekerjaan Umum dan Perumahan Rakyat No. 14/PRT/M/2017 tentang Persyaratan Kemudahan Bangunan Gedung, harus dapat diakses oleh semua termasuk penyandang disabilitas . Namun, itu tidak berarti bahwa Islam menyebabkan kesulitan bagi umat Islam untuk melakukan shalat mereka, memang mereka percaya bahwa shalat dapat dilakukan dengan cara yang berbeda tergantung pada kondisi spesifik yang berbeda, seperti yang dikatakan dalam Al Qur'an melakukan shalat oleh duduk untuk mereka yang tidak dapat berdiri, atau dengan berbaring untuk mereka yang tidak dapat meninggalkan tempat tidurnya karena sakit, dan sebagainya.

Penerapan konsep desain universal pada bangunan masjid diharapkan akan membuat penyandang disabilitas lebih mandiri serta merasa aman dan nyaman untuk mengakses sebuah bangunan masjid. Penelitian ini bertujuan untuk mengetahui penerapan desain universal pada interior mesjid bagi muslim dan muslimah penyandang disabilitas sehingga mereka dapat mengakses sholat secara mandiri. Studi kasus dilakukan terhadap masjid Manarul Amal di Universitas Mercu Buana.

\section{Tinjauan Literatur}

\section{Definisi Desain Universal}

Ada beberapa pengertian Universal Design yang secara prinsip sama dengan detail redaksional yang berbeda dari beberapa sumber, di antaranya sebagai berikut:

1. Universal design means simply designing all products, building and exterior spaces to be usable by all people to the greatest extent possible (Mace).

2. Universal design can be defined as the design of products and environments to be usable to the greatest extent possible by people of all ages and abilities (Story et al.).

3. Universal design is an approach to design that incorporates products as well as building features and elements which, to the greatest extent possible, can be used by everyone (Mace).

Desain universal yang akan dibahas dalam tulisan berikut lebih dipahami sebagai sebuah pendekatan dalam desain. Desain universal adalah sebuah pendekatan desain untuk menghasilkan fasilitas dan juga produk bagi semua orang (sebagai pengguna) secara umum, tanpa batasan fisik, rentang usia, dan juga jenis kelamin. Dengan pendekatan desain tersebut, suatu fasilitas maupun produk akan mengalami kompromi sehingga semua orang sebagai 
pengguna dapat diakomodasi kebutuhannya dalam beraktivitas, tanpa mengeksklusifkan sebagian orang.

Desain yang baik dan dilengkapi dengan perhatian terhadap isu faktor manusia pengguna dapat menjadi kunci pemecahan masalah dalam desain universal. Isu faktor manusia tersebut berkaitan dengan kondisi fisik manusia dalam penggunaan produk desain, dan menjadi standar prinsip-prinsip dalam pendekatan desain universal. Prinsip-prinsip dalam desain universal menurut Story et al. (34-35) adalah sebagai berikut : 1) Equitable Use adalah desain yang dapat digunakan secara wajar oleh semua orang dengan variasi kemampuannya dan tidak menstigmakan penggunanya; 2) Flexibility in Use adalah desain yang fleksibel dan dapat mengakomodasi kebutuhan aktivitas semua orang (sebagai pengguna) secara umum, tanpa batasan fisik, rentang usia, dan juga jenis kelamin; 3) Simple and Intuitive Use adalah desain yang cara penggunaannya mudah dimengerti, tanpa tuntutan pengalaman penggunaan, pengetahuan, dan kemampuan bahasa tertentu; 4) Perceptible Information adalah desain yang mengkomunikasikan atau mengakomodasikan informasi dengan efektif kepada pengguna, dan dekat dengan kondisi ambang dan atau kemampuan sensor pengguna; 5) Tolerance for Error adalah desain yang meminimalkan dampak dan konsekuensi kecelakaan atau kejadian yang tidak diinginkan dari tindakan yang keliru; 6) Low Physical Effort adalah desain yang dapat digunakan secara efisien dan nyaman dengan usaha kekuatan fisik minimal (tidak melelahkan); dan 7) Size and Space for Approach and Use adalah desain dengan terapan ukuran dan ruang yang mudah (cukup) untuk pencapaian, dan dapat digunakan tanpa batasan ukuran, postur, dan mobilitas pengguna.

Prinsip-prinsip tersebut berlaku umum bagi semua bidang rancangan arsitektur, interior, produk, dan lain-lain, terutama berupa fasilitas fisik masjid. Secara khusus, prinsipprinsip tersebut juga bisa diterapkan untuk fasilitas ruang mesjid untuk pengunjung penyandang disabilitas pada saat beribadah.

\section{Penerapan Konsep Desain Universal bagi Penyandang Disabilitas}

Konsep desain universal dapat diterapkan beberapa konsep rancangan yang diperuntukkan masing-masing penyandang disabilitas terhadap elemen interior dengan menggunakan acuan standar dan regulasi Permen PUPR No 14/PRT/M/2017 sebagai berikut:

1. Penyandang disabilitas daksa (pengguna kursi roda, kru tongkat)

Sebuah rancangan ruang publik, contoh yang berlokasi di Arizona, Amerika Serikat memberikan fasilitas universal bagi para penikmat taman yang memiliki agenda keseharian tersendiri dalam melintas, bersantai, dan berbincang. Penempatan ramp pada ruang publik bukan lagi hal yang asing karena ramp adalah solusi terbaik yang sukses menggantikan fungsi tangga bagi kaum pengguna kursi roda untuk berpindah tempat secara leluasa.

Masalah akan sulitnya beraktivitas secara efektif dikarenakan keterbatasan fisik, yang secara langsung menghambat akses bepergian seseorang, menjadi pudar dengan adanya jalur ramp. Di samping fungsi dari elemen desain yang diterapkan, taman publik memiliki identitas sebagai ruang ekspresi, yang mengutamakan estetika dimana hal yang dapat menarik perhatian orang-orang baik disekitar untuk singgah.

Ramp yang di desain secara maksimal dimana menggabungkan konteks dan penghijauan yang kontras dengan cuaca ekstrim di Arizona membuat pengalaman perjalanan seseorang lebih berkesan. Terselubung kalkulasi tinggi di setiap penempatan elemen pada komposisi desain, jika dilakukan dengan benar maka dapat menorobos pembatasan fisik dan mental para pengguna sehingga dapat menghubungkan dengan masyarakat. 
2. Penyandang disabilitas netra

Pusat penyandang disabilitas tuna netra yang dirancang secara spesifik oleh Mauricio Rocha mendatangkan totalitas kenyamanan bagi kaum tuna netra menjalani keseharian (Taller de Arquitectura-Mauricio Rocha). Relasi antar ruang dan struktur diolah dengan penuh kontras; dari wujud tekstur, ukuran besar, berat, dan jenis material yang dipilih untuk meningkatkan daya kerja indera-indera lainnya untuk berfungsi lebih aktif dalam menerjemahkan konsisi sekitarnya.

Seperti alunan suara gemercik udara dirancang untuk mengarahkan tujuan, tekstur dinding yang membentuk motif bangunan yang membedakan motif horisontal dan vertikal untuk menjadi informasi dalam menandakan setiap bangunan serta fungsinya, dan tanaman yang memiliki harum yang kuat ditanam pada area terbuka agar dapat merangsang orientasi akan konteks di sekeliling bangunan ini.

Terselubung kalkulasi tinggi di setiap penempatan elemen pada komposisi desain, jika dilakukan dengan benar maka dapat menorobos batasan fisik dan mental para pengguna dapat menghubungkan mereka dengan masyarakat.

3. Penyandang disabilitas rungu

Stelzhamerschule School-Linz, Austria yang dirancang secara spesifik oleh Kirsch Arsitek mendatangkan totalitas kenyamanan bagi kaum tuna rungu menjalani keseharian (KIRSCH Architecture). Relasi antar ruang dan struktur diolah dengan mengutamakan orientasi visual yang tinggi serta mendorong totalitas pengalaman indera lainnya yang didasari oleh filosofi Deaf Space (desain ruang tuli).

Prinsip-prinsip dari Deaf Space ditujukan untuk meluaskan kemampuan seseorang dalam merespon ruang dengan rentang keterbatasan 180 derajat. Transparansi dari setiap ruang dapat mencegah limitasi seseorang dalam menangkap aktivitas di ruangan lain dan memaksimalkan space awareness (meningkatkan kesadaran) menjadi 360 derajat. Penggunaan ramp jalan sebagai titik temu yang mencegah tabrakan antar individu, elemen repetisi yang berbeda seperti garis-garis pada dinding dan jalan setapak yang disusun untuk dapat memberikan navigasi secara naluri, serta penggunaan warna yang kontras dengan kulit seperti biru atau hijau agar mepermudah membaca gerakan bahasa isyarat dari jarak yang lebih jauh sangat membantu kaum tuna rungu untuk memaksimalkan indera-indera lainnya,

Terselubung kalkulasi tinggi di setiap penempatan elemen pada komposisi desain, jika dilakukan dengan benar maka dapat menorobos pembatasan fisik dan mental para pengguna dapat menghubungkan mereka dengan masyarakat.

\section{Penyandang Disabilitas terhadap Persepsi}

Menurut Robbins (2006), persepsi adalah proses yang digunakan individu mengelola dan menafsirkan kesan indera mereka dalam rangka memberikan makna kepada lingkungan mereka. Meski demikian apa yang dipersepsikan seseorang dapat berbeda dari kenyataan yang obyektif. Persepsi merupakan suatu proses yang didahului oleh proses penginderaan yaitu merupakan proses diterimanya stimulus oleh individu melalui alat indera namun proses itu tidak berhenti begitu saja melainkan stimulus tersebut diteruskan dan proses selanjutnya merupakan proses persepsi (Terok).

Proses pembentukan persepsi adalah objek menimbulkan stimulus dan stimulus mengenai alat indera atau reseptor, perlu dikemukakan antara objek dan stimulus itu menjadi 
satu misalnya dalam hal tekanan. Benda sebagai objek langsung mengenai kulit sehingga akan terasa tekanan tersebut. Proses stimulus mengenai alat indera diteruskan oleh syaraf sensoris ke otak proses ini disebut sebagai proses psiologis. Kemudian terjadilah proses diotak sebagai pusat kesadaran sehingga individu menyadari apa yang dilihat dan apa yang didengar atau apa yang diraba. Proses yang terjadi diotak atau dalam pusat kesadaran ini yang disebut proses psikologis. Dengan demikian dapat dikemukakan terakhir dari proses persepsi ialah individu menyadari tentang misalnya apa yang dilihat, apa yang didengar dan apa yang diraba yaitu stimulus yang diterima oleh alat indera, proses ini merupakan proses terakhir dari persepsi dapat diambil oleh individu dalam berbagai macam bentuk.

Persepsi dalam arsitektur dan desain interiori adalah proses memperoleh atau menerima informasi dari lingkungan (Laurens). Teori atau pendekatan tentang bagaimana manusia mengerti dan menilai lingkungannya ini dikelompokkan ke dalam dua kelompok :

1. Pendekatan konvensional

Pendekatan yang berdasarkan sensori atau stimuli. Teori ini menganggap adanya rangsangan dari luar diri individu (stimulus). Jika sejumlah pengindraan disatukan dan dikordinasikan di dalam pusat saraf yang lebih tinggi (otak) maka manusia bisa mengenali dan menilai suatu objek. Proses diterimanya rangsangan sampai rangsangan itu disadari dan dimengerti oleh individu yang bersangkutan inilah yang disebut dengan persepsi.

\section{Pendekatan Ekologis}

Pendekatan yang berdasarkan informasi. Pendekatan ini mengemukakan bahwa seorang individu tidaklah menciptakan makna dari apa yang diindrakannya. Sesungguhnya makna itu telah terkandung dalam stimulus itu sendiri dan tersedia untuk organisme yang siap menyergapnya. Persepsi ini terjadi secara spontan dan langsung. Jadi bersifat holistik. Spontanitas ini terjadi karena manusia melibatkan setiap objek yang ada dalam lingkungannya dan setiap objek menonjolkan sifat-sifatnya yang khas untuk organisme tersebut. Penampilan makna ini disebut affordances.

Affordances atau kemanfaatan setiap objek adalah khas untuk setiap mahluk. Misalnya, pohon, memberi sifat teduh, rindang untuk manusia, mungkin untuk serangga atau beinatang lain pohon itu mempunyai manfaat yang berbeda, misalnya sebagai sarangnya. Dengan perkataan lain, objek atau stimuli itu sendiri pun aktif berinteraksi dengan mahluk yang mengindra sehingga timbullah makna spontan tersebut.

Tingkat persepsi dan penafsiran karya arsitektur yang dilakukan pengamat/pengguna tergantung pada (Laurens) :

1. Tingkat pengalaman,

2. Kemampuan pribadi,

3. Faktor emosional, dan

4. Sosio kultural pengamat.

Persepsi pengunjung terhadap tingkat kemandirian ruang berdasarkan konsep desain universal yang terkait untuk mendapatkan hasil sebagai berikut:

\begin{tabular}{|c|c|c|}
\hline$\overline{\text { No }}$ & Pengguna & $\begin{array}{c}\text { Persyaratan desain dasar yang dapat diakses terhadap perspepsi } \\
\text { pengguna }\end{array}$ \\
\hline 1 & $\begin{array}{l}\text { Disabilitas } \\
\text { pendengaran } \\
\text { (Tunarungu/Tuli } \\
\text { dan kurang dengar) }\end{array}$ & $\begin{array}{l}\text { - informasi panduan/signage di pintu masuk } \\
\text { - papan nama (sholat / sholat, khotbah / pidato, azan / panggilan sholat) } \\
\text { di menara masjid (dengan warna), di wudhu, di kamar mandi } \\
\text { - menerapkan prinsip kerja TV text, LCD, monitor sebagai tampilan } \\
\text { khutbah }\end{array}$ \\
\hline
\end{tabular}




\begin{tabular}{|c|c|c|}
\hline & & $\begin{array}{l}\text { - dimensi lebar koridor maksimum } 160 \mathrm{~cm} \text {, dinding persimpang sudut } \\
\text { melingkar } \\
\text { - pencahayaan terang dan tidak muram/silau } \\
\text { - warna material kaca pintu, dinding tidak bertektur } \\
\text { - bel alarm visual darurat di kamar mandi } \\
\text { - penandaan, pelabelan, dan tampilan informasi yang jelas dan konsisten } \\
\text { dan lengkap }\end{array}$ \\
\hline 2 & $\begin{array}{l}\text { Disabilitas } \\
\text { penglihatan (tuna } \\
\text { netra, low vision) }\end{array}$ & $\begin{array}{l}\text { - peta sentuhan di pintu masuk } \\
\text { - guiding blok / jalur pemandu /ubin peringatan untuk mencapai langkah } \\
\text { - ramp- jalur pedestrian permukaan rata dan tidak lubang/rusak } \\
\text { - handrail } \\
\text { - tanaman braille di susuran tangga }\end{array}$ \\
\hline 3 & $\begin{array}{l}\text { Disabilitas Fisik } \\
\text { Amputasi } \\
\text { kaki/tangan }\end{array}$ & $\begin{array}{l}\text { - akses kamar mandi } \\
\text { - akses kamar wudhu } \\
\text { - tempat parkir yang dapat diakses } \\
\text { - ruang sholat yang dapat diakses } \\
\text { - handrail sesuai ketinggian } \\
\text { - kebutuhan ruang di area sirkulasi dan lebar pintu } \\
\text { - ketentuan alternatif akan diperlukan, seperti langkah-langkah serta } \\
\text { landai dan sempit bilik }\end{array}$ \\
\hline 4 & $\begin{array}{l}\text { Pengguna kursi } \\
\text { roda/ } \\
\text { Wheelchair }\end{array}$ & $\begin{array}{l}\text { - semua jenis perlengkapan, kontrol, dan peralatan harus ditempatkan } \\
\text { dalam jangkauan yang sempit } \\
\text { - lebar minimum dan persyaratan ruang } \\
\text { - perubahan level harus dinegosiasikan dengan jalan landai atau lift } \\
\text { - permukaan lantai harus rata/halus dan keras }\end{array}$ \\
\hline 5 & Lansia / manula & $\begin{array}{l}\text { - akses kamar mandi } \\
\text { - akses kamar wudhu dilengkapi dengan bangku } \\
\text { - handrail }\end{array}$ \\
\hline 6 & Anak-anak & $\begin{array}{l}\text { - akses kamar mandi } \\
\text { - akses kamar wudhu dilengkapi dengan perlengkapan air yang lebih } \\
\text { rendah }\end{array}$ \\
\hline
\end{tabular}

\section{Standar Aksesibilitas}

Dalam penyediaan aksesibilitas fisik bagi penyandang cacat dibutuhkan sarana yang khusus sesuai dengan individu ketunaan masing-masing. Adapun sarana aksesibilitas fisik bagi tuna daksa pada ruang dan bangunan meliputi (Gazalba) : (1) Ukuran dasar ruang gerak, (2) Perabot, (3) Pintu masuk, (4) Jalur penghubung, (5) Ramp (tanjakan), (6) Toilet, (7) Urinal, (8) Washtafel, (9) Pancuran/keran wudlu.

Aksesibilitas fisik sebagai fasilitas kemudahan untuk mobilitas tuna daksa dalam melakukan aktifitas harus memiliki ukuran yang sesuai dengan standar dan persyaratan yang berkaitan dengan perilaku sosial penggunanya. Berikut uraian tentang ukuran standar aksesibilitas berdasarkan kajian literatur dan pedoman dari Permen PUPR No. 14/PRT/M/2017.

\section{Metode Penelitian}

Metode peneltian yang digunakan metode kualitatif deskriptif dan kuantitatif (Moleong). Penelitian kuantitatif diperlukan agar peneliti bisa memperoleh gambaran yang lebih terukur tentang penerapan desain universal. Peneliti menggunakan indikator-indikator desain universal yang jelas dan terukur ketika turun ke lapangan dan melihat masjid-masjid yang 
menjadi objek penelitian. Indikator diadopsi dari buku panduan yang dikeluarkan oleh Permen PUPR No 14/PRT/M/2017. Sementara penelitian kualitatif diperlukan untuk memperdalam data-data historis dan deskriptif untuk menemukan konteks yang lebih luas dari masalah desain universal di masjid-masjid yang diteliti. Peneliti melakukan wawancara dengan pihak-pihak yang terlibat di masjid dan berusaha menemukan persepsi mereka tentang berbagai aspek yang dijadikan alat ukur kuantitaif tadi. Data observasi di lapangan yang telah terkumpul selanjutnya dianalisis kesesuaiannya dengan data literatur. Proses analisis data yang dilakukan untuk mengidentifikasi penerapan desain universal pada masjid Manarul' Amal, sehingga dapat memberikan solusi desain universal untuk perkembangan masjid Manarul' Amal selanjutnya.

\section{Hasil dan Pembahasan}

\section{Deskripsi Objek}

Masjid Manarul'Amal merupakan masjid yang terdapat di lingkungan Universitas Mercu Buana yang beralamat di Jalan Meruya Selatan No. 1, RT.01 / RW.08, Meruya Selatan, Kembangan, RT.1/RW.8, RT.1/RW.8, Meruya Selatan, Kembangan, Kota Jakarta Barat (Biro MGS UMB).

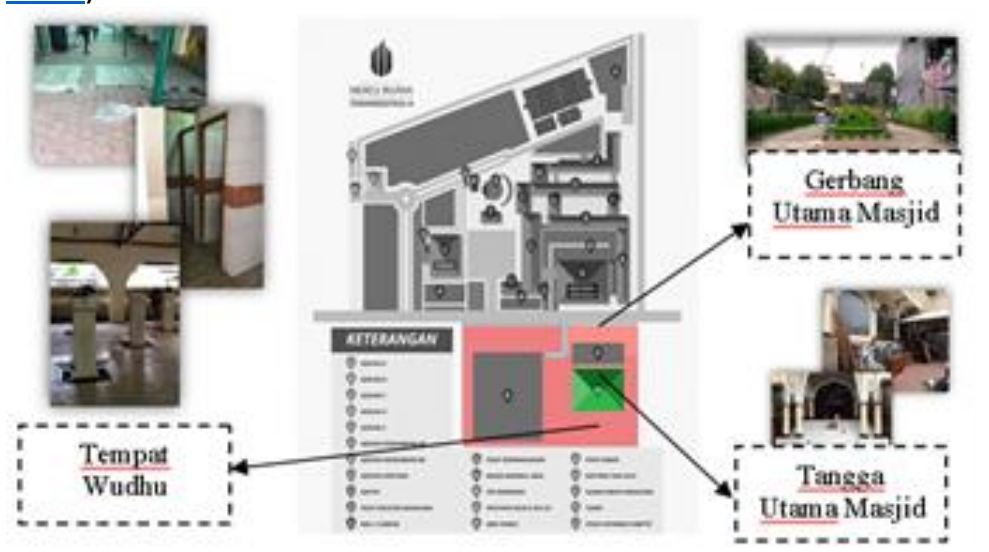

Gambar 1 Deskripsi Objek.

Sumber : dok. Tim peneliti

Penerapan desain universal pada masjid Manarul' Amal dianalisis dengan mengklasifikasikan faktor-faktor pada sirkulasi yaitu jalur pedestrian. Klasifikasi didasarkan pada parameter desain universal yang dapat digunakan untuk menentukan tingkat kesesuaian faktor desain universal dengan literatur atau standar desain universal.

Data lapangan atau objek yang ada dibandingkan atau dikomparasikan dengan data literatur untuk menemukan hasil analisis data. Dari hasil klasifikasi faktor dan hasil analisis data, faktor yang kurang sesuai dengan standar desain universal akan diberi usulan solusi desain untuk permasalahan yang ada pada masjid Manarul' Amal.

Dari hasil analisis data dan solusi desain yang ada akan ditemukan kesimpulan dari penerapan desain universal di masjid Manarul' Amal di Universitas Mercu Buana. Berikut hasil analisa masjid Manarul' Amal. 

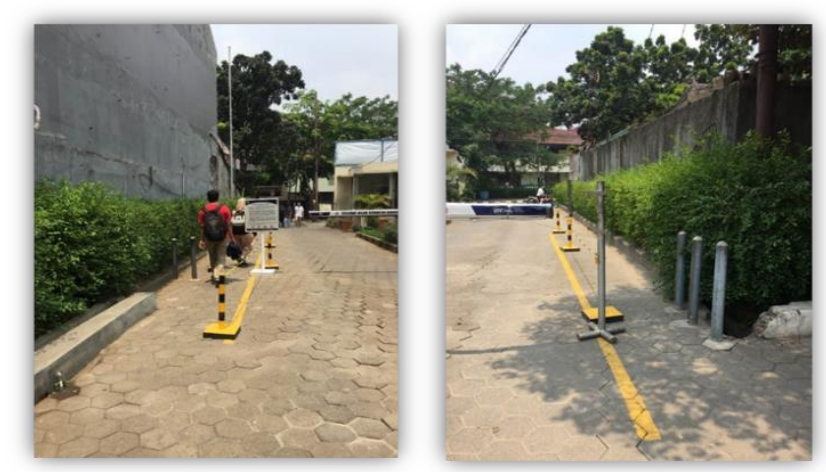

Gambar 2 Gerbang Utama Masjid (Area 1)

Sumber : dok. Tim peneliti

Ukuran lebar masuk pejalan kaki adalah $50 \mathrm{~cm}$. Secara umum lebar jalur ini tidak nyaman digunakan untuk pejalan kaki. Dan juga tidak terdapat jalur khusus untuk pengguna kursi roda dan juga bagi difable tuna netra karena tidak terdapat jalur pemandu (Guiding Block).

Sehingga area ini belum memenuhi prinsip desain universal ke 1,3 dan 7.
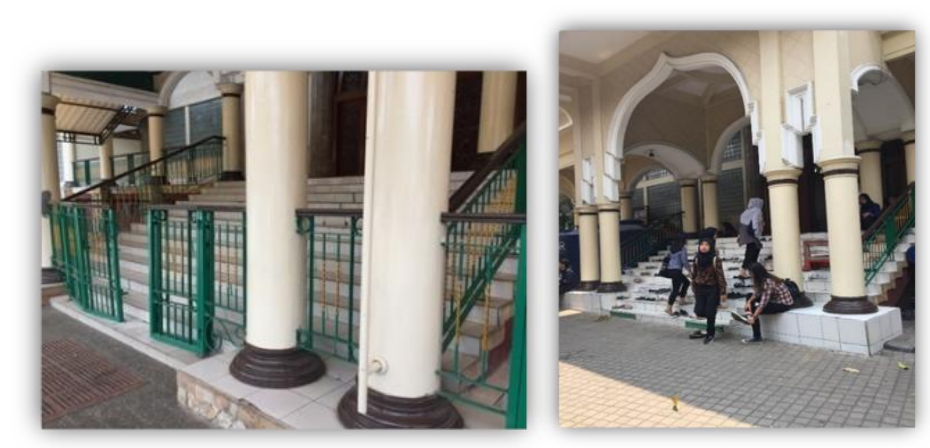

Gambar 3 Tangga Utama Masjid (Area 2)

Sumber : dok. Tim peneliti

Pada area tangga masjid sudah menerapkan ukuran standar dan terdapat handrail pada tangga area masjid untuk orang yang sudah lanjut usia. Tetapi pada area tersebut tidak terdapat ramp untuk para penyandang disabilitas, sehingga area ini belum memenuhi prinsip desain universal ke 1 dan 4.
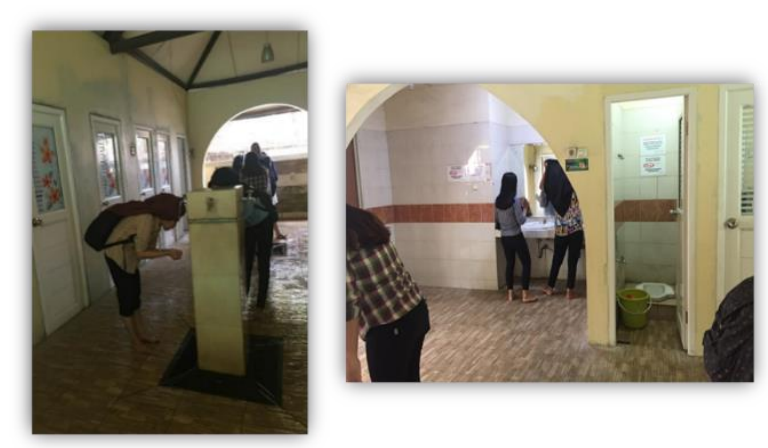

Gambar 4 Area Wudhu (Area 3)

Sumber : dok. Tim peneliti 
Untuk area wudhu tidak terdapat handrail yang dapat menyulitkan penyandang disabilitas dan lanjut usia untuk berwudhu. Dan pada area kamar kecil tidak akses untuk pengguna kursi roda, sehingga area ini belum memenuhi prinsip desain universal ke 1,5 dan 7.

Kesimpulan berisikan hasil dari analisa yang dilakukan dengan berdasarkan 7 prinsip desain universal yang disusun ke dalam tabel.

Tabel 1 Kesimpulan Hasil Analisis

\begin{tabular}{|c|c|c|c|c|c|c|c|c|c|}
\hline \multirow{2}{*}{ No } & \multirow{2}{*}{ Area } & \multicolumn{7}{|c|}{ Universal Design Principles } & \multirow{2}{*}{ Perlu Solusi } \\
\hline & & EU & FU & SIU & $\mathrm{PI}$ & TE & LPE & SFAU & \\
\hline 1 & $\stackrel{\mathbb{d}}{\frac{\mathbb{L}}{<}}-$ & $x$ & $\checkmark$ & $x$ & $\checkmark$ & $\checkmark$ & $\checkmark$ & $x$ & EU, SIU dan SFAU \\
\hline 2 & $\stackrel{\mathbb{d}}{\stackrel{\alpha}{\alpha}} \sim$ & $x$ & $\checkmark$ & $\checkmark$ & $x$ & $\checkmark$ & $\checkmark$ & $\checkmark$ & EU dan PI \\
\hline 3 & $\stackrel{\mathbb{D}}{\frac{1}{2}} m$ & $x$ & $\checkmark$ & $\checkmark$ & $\checkmark$ & $x$ & $\checkmark$ & $x$ & EU, TE dan SFAU \\
\hline
\end{tabular}

Terlihat tabel di atas menunjukkan berdasarkan kesimpulan hasil analisa diatas dapat disimpulkan bahwa beberapa Akses Sistem (jalur pedestrian) masih memerlukan solusi desain berdasarkan tujuh prinsip desain universal.

Analisis Hasil Observasi

1. Responden

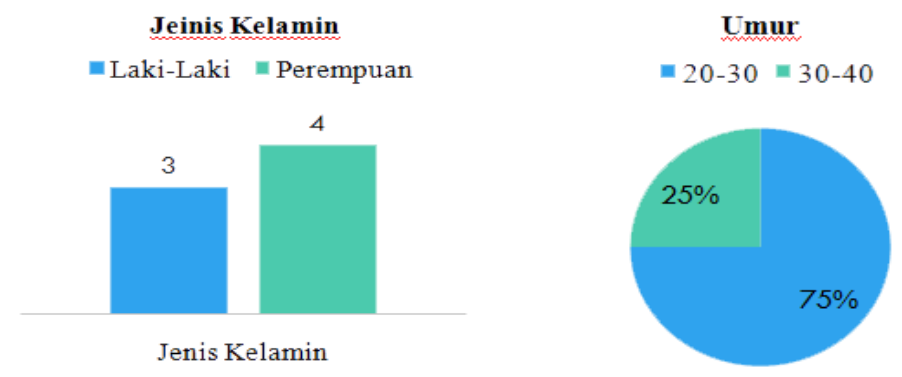

2 Presentase Hasil Quisioner

Presentase Hasil Quisioner

| Sangat Tidak Baik || Tidak Baik ||Cukup Baik || Baik || Sangat Baik

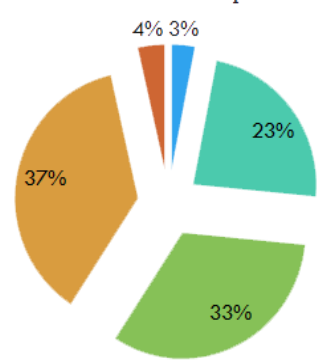


Berdasarkan hasil presentase quisioner di atas dapat disimpulkan bahwa sirkulasi Masjid Manurul'Amal dapat dikatakan tidak akses 4\%, maka perlu di lakukan kajian lebih lanjut dengan memberikan alternatif atau solusi desain.

\section{Solusi Desain}

Berikut ini adalah titik lokasi yang akan dibuatkan desain baru (solusi desain) berdasarkan hasil analisa yang telah dilakukan.

\section{Gerbang Utama Masjid}
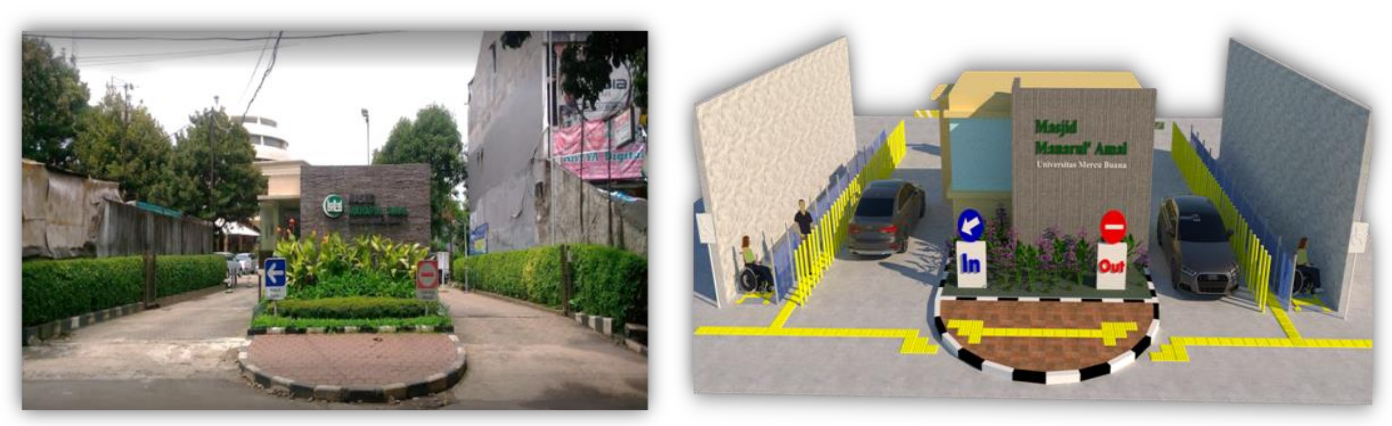

Gambar 6 Desain Lama (Existing) Gerbang Utama Masjid

Sumber : dok. Tim peneliti

\section{Deskripsi :}

1. Tidak ada jalur khusus disabilitas.

2. Tidak terdapat guiding block.

3. Permukaan jalan yang tidak rata
Gambar 7 Desain Baru (Solusi Desain) Gerbang Utama Masjid. Digambar : Tim peneliti

Solusi desain :

1. Terdapat jalur disabilitas dengan lebar $\mathbf{1 4 0}$ $\mathrm{cm}$.

2. Terdapat pemisah antara pengguna kursi roda dengan pejalan kaki.

3. Terdapat signage.

4. Terdapat jalur guiding block.

5. Permukaan jalan yang sudah rata (cor).

Tangga Utama Masjid
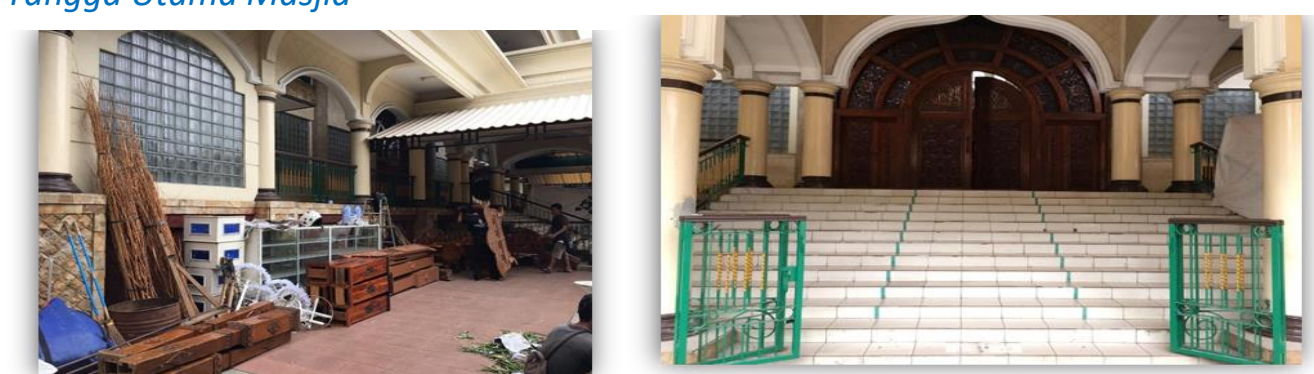

Gambar 8 Desain Lama (Existing) Tangga Utama Masjid

Sumber : dok. Tim Peneliti

Deskripsi :

1. Tidak terdapat ramp.

2. Tidak terdapat signage.

3. Tidak terdapat step nosing pada anak tangga.

4. Tidak terdapat rack sepatu/sandal. 


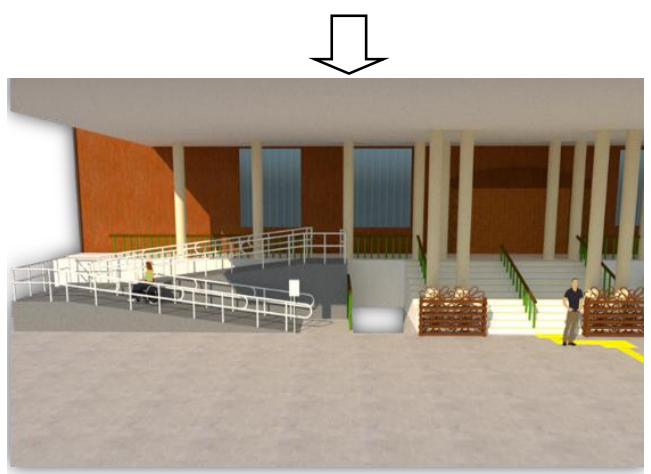

Solusi desain :

1. Terdapat ramp dengan lebar $180 \mathrm{~cm}$ dan panjang $9 \mathrm{~m}$.

2. Terdapat guiding block.

3. Terdapat step nosing pada anak tangga.

4. Terdapat rack sepatu/sandal.

5. Terdapat handrail pada pertengahan tangga.

Gambar 9 Desain Baru (Solusi Desain) TanggaUtama Masjid

Digambar : Tim Peneliti

\section{Jalan Menuju Tempat Wudhu}

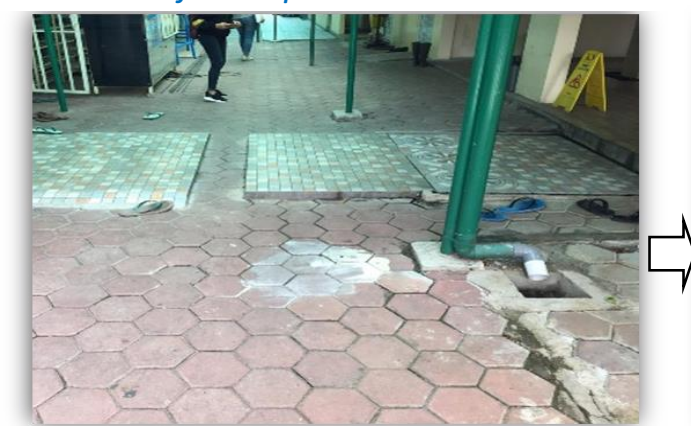

Gambar 10 Desain Lama (Existing) Jalan Menuju Tempat Wudhu Sumber : dok. Tim Peneliti

Deskripsi :

1. Tidak terdapat jalur khusus kursi roda.

2. Tidak terdapat guiding block.

3. Jalan tidak rata.

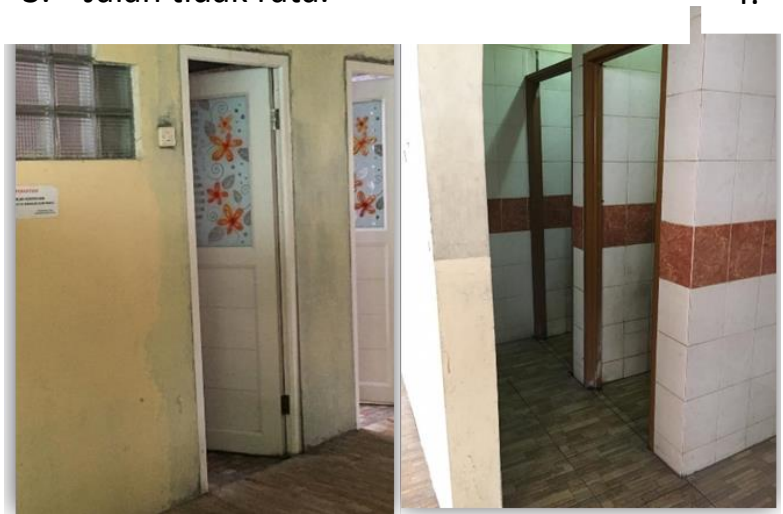

Gambar 11 Desain Lama (Existing) Toilet Sumber : dok. Tim Peneliti

Deskripsi :

1. Tidak terdapat handrail .

2. Toilet tidak access.

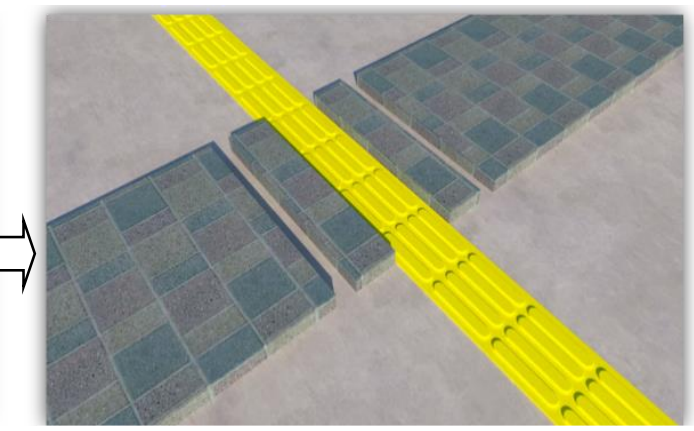

Gambar 11 Desain Baru (Solusi Desainng) Jalan Menuju Tempat Wudhu Digambar: Tim Peneliti Solusi desain

1. Sudah terdapat jalur khusus kursi roda (panjang sumbu roda kursi roda $80 \mathrm{~cm}$ )

2. Jalur orang berjalan di tengah.

3. Sudah terpasang guiding block.

4. Jalan sudah rata (cor)

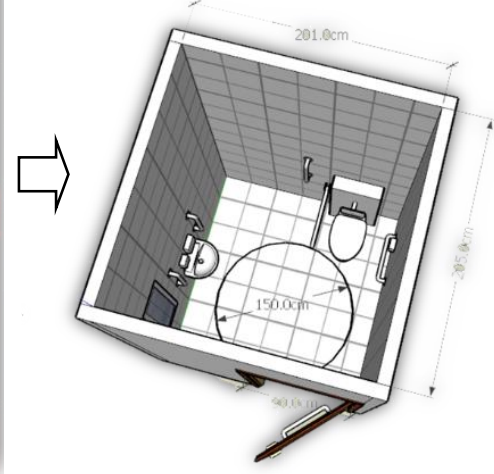

Gambar 12 Desain Baru (Solusi Desain) Toilet Digambar : Tim Peneliti

Solusi desain :

1. Toilet sudah access dengan ukuran $2 \mathrm{x}$ $2 \mathrm{~m}$ dengan lebar pintu $90 \mathrm{~cm}$.

2. Terdapat handrail.

3. Bukaan pintu ke luar. 
Tempat Wudhu

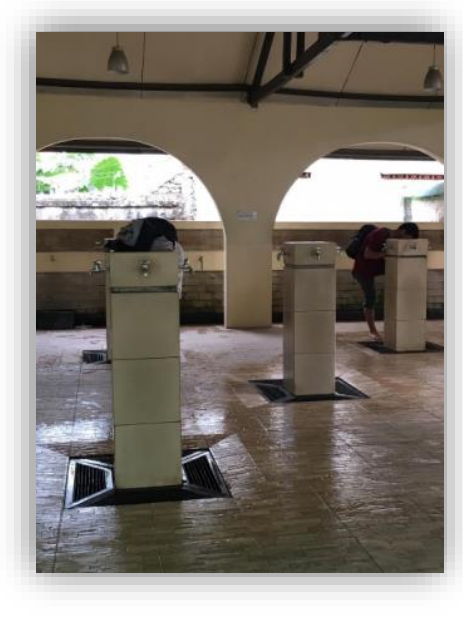

Gambar 13 Desain Lama

(Existing) Tempat Wudhu

Sumber : dok. Tim Peneliti

Deskripsi :

Tidak terdapat handrail dan guiding block.

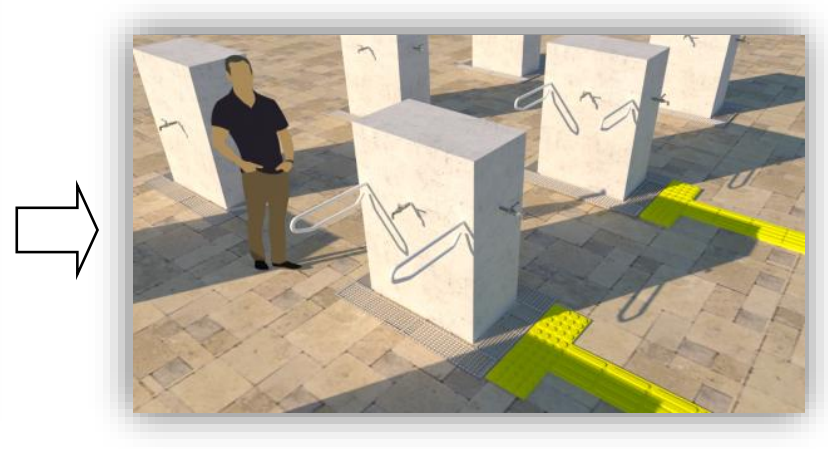

Gambar 14 Desain Baru (Solusi Desain)

Tempat Wudhu

Digambar : Tim Peneliti

Solusi desain :

1. Pada bagian wudhu sudah terpasang handrail dan guiding block.

2. Jarak antar block wudhu $152.4 \mathrm{~cm}$

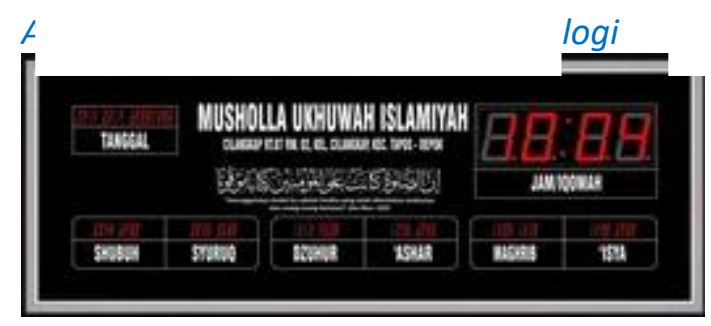

Gambar 15 Jadwal sholat dengan digital. Sumber : www.google.com/alwakita_digital

Gambar 16 Sistem lampu alarm (signal) dan bel alarm 3 titik warna lampu. Digambar : Tim peneliti

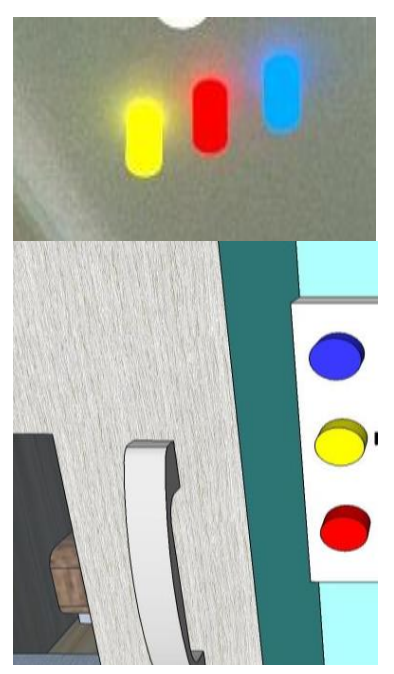

Terlihat gambar 15 menunjukkan beberapa masjid menggunakan atribut-atribut fasilitas mendukung berupa alat tambahan untuk menginformasikan waktu sholat. Papan jadwal sholat adalah instrumen umum yang ditemukan di interior masjid. Ini terdiri dari lima titik jam pada 
setiap waktu sholat, sementara tipe lainnya dilengkapi dengan jam tangan nyata yang sedang berjalan.

Terlihat gambar 16 menunjukkan bahwa sistem lampu alarm (signal) 3 titik lampu berbeda yang meletakkan di luar dinding dekat diatas pintu masuk. Tiga titik lampu yang berbeda yaitu lampu warna biru, merah dan kuning yang bekerja sama dengan menggunakan tabung flash xenon dengan lampu strobo intentitas tinggi atau boleh seperti lampu lalu lintas. Lampu biru menginformasikan bahwa shalat akan segera dimulai, lampu warna kuning memberi tahu bahwa masih ada banyak waktu sebelum shalat dimulai. Lampu-lampu akan dinyalakan setelah adzan dan dimatikan tepat sebelum sholat dimulai. Sementara lampu merah menginformasikan bahwa shalat sudah dimulai.

\section{Simpulan}

Setelah dianalisis dan dievaluasi keadaan jalur pedestrian Masjid Manarul' Amal dan membandingkan dengan teori, maka untuk jalur pedestrian Masjid Manarul' Amal belum seluruhnya menerapkan desain universal, terutama pada jalur pedestrian seperti gerbang masuk masjid, tangga masjid, jalan menuju tempat wudhu maupun tempat wudhunya itu sendiri dan bahkan juga atribut fasilitas mendukung alat bantu teknologi. Namun dibutuhkan sebuah solusi desain (desain baru) dengan berdasarkan 7 prinsip universal design yang telah ada.

1. Penerapan solusi desain yang pertama yaitu pada fasilitas universal seperti gerbang utama masjid yang memiliki permasalahan dalam penerapan desain universal, sehingga diberikan solusi desain yang sesuai dengan standar desain universal. Pada gerbang utama masjid diberi jalur khusus kursi roda dan guiding block untuk penyandang tuna netra, dimensi akses disesuaikan dengan standar desain universal.

2. Penerapan solusi desain yang kedua yaitu pada bagian tangga utama masjid yang memiliki permasalahan desain universal, pada area ini di tambahkan ramp untuk mempermudah akses untuk kursi roda maupun troli untuk membawa barang. Kemudian pada bagian ujung tangga dibuat rack sepatu agar tidak menggangu akses tangga dari sepatu atau sandal yang berserakan.

3. Penerapan solusi desain yang ketiga yaitu pada akses jalan menuju tempat wudhu dimana tidak terdapat jalur kursi roda, oleh karena itu dibuat jalur kursi roda dengan panjang sumbu kursi roda adalah $80 \mathrm{~cm}$.

4. Penerapan solusi desain yang keempat yaitu pada area toilet yang tidak akses, sehingga diberikan solusi desain berupa toilet akses berukuran $2 \times 2 \mathrm{~m}$ dan terdapat handrail di dalamnya untuk mempermudah akses bagi orang yang memiliki keterbatasan fisik.

5. Penerapan solusi desain yang terakhir yaitu pada area tempat wudhu yang belum akses untuk penyandang disabilitas, oleh karena itu dibuat solusi dengan mengaplikasikan handrail dan guiding blok pada tempat wudhu.

Hendaknya seluruh jalur pedestrian pada Masjid Manarul' Amal menerapkan desain universal dan dengan solusi desain yang telah dirancang, pihak masjid mendapatkan referensi ataupun gambaran untuk membuat jalur pedestrian masjid Manarul' Amal yang dapat dipakai secara universal, sebenarnya jika desain universal diterapkan, sangat banyak dampak positif yang ditimbulkan termasuk kemandirian dan kenyamanan bagi penyandang disabilitas. 


\section{Daftar Pustaka}

"Peraturan Menteri Pekerjaan Umum Dan Perumahan Rakyat No. 14/Prt/M/2017 Tentang Persyaratan Kemudahan Bangunan Gedung." Departemen Pekerjaan Umum, 2017.

"Undang-Undang Penyandang Disabilitas No. 8 Tahun 2016." 2016.

Biro MGS UMB. "Data Site Plan Dan Denah Interior Perpustakaan Kampus Meruya Umb." 2018.

Gazalba, Sidi. Masjid Pusat Ibadat Dan Kebudayaan Islam. Pustaka Al Husna, 1994.

KIRSCH Architecture. "Stelzhamerschule Linz." 2016, https://www.archdaily.com/781415/stelzhamerschule-linz-kirsch-architecture.

Laurens, Joyce Marcella. Arsitektur Dan Perilaku Manusia. Penerbit PT Grasindo, 2005.

Mace, Ronald. "Accessible Environments: Toward Universal Design." Design Interventions: Toward a More Humane Architecture, Van Nostrand Reinhold, 1991.

---. Universal Design: Housing for the Lifespan of All People. The Center for Universal Design, Nort Carolina State University, 1988.

Moleong, Lexy J. Metodologi Penelitian Kualitatif Edisi Revisi, Cetakan Keduapuluh Dua. PT. Remaja Rosdakarya Offset, 2006.

Story, Molly Follette et al. The Universal Design File: Designing for People of All Ages and Abilities. Center for Universal Design, NC State University,, 1998.

Taller de Arquitectura-Mauricio Rocha. "Center for the Blind and Visually Impaired." 2011, https://www.archdaily.com/158301/center-for-the-blind-and-visually-impaired-tallerde-arquitectura-mauricio-rocha.

Terok, Ferdinan S.R.P. "Persepsi Masyarakat Terhadap Elemen Street Furniture Pedestrian Koridor Jalan. Piere Tendean." Arsitektur, vol. Magister (S2), Thesis, Universitas Sam Ratulangi, 2015. 